\title{
GENETICAL AND CYTOLOGICAL STUDIES IN ALLIUM
}

\section{TWO GENES IN A. FISTULOSUM}

\author{
ATUSI YAMAURA
}

\author{
Metropolitan Kitazono High School
}

Received December 15, 1953

UDC $575.1: 576.3: 582.5: 72.2$

Since Tschermak's studies (1916) the genic analysis of morphological and physiological traits in the onion, $A$. Cepa, has been continued by foreign investigators. No studies, however, dealing with $A$. fistulosum, which is more familiar to us than the former species, have been undertaken.

The writer found in 1945 a genetic variant of $A$. fistulosum, which is almost unable to excrete wax on the epidermis of its tubal leaves; the color of the leaves being somewhat yellowish green compared with the waxy green color of the normal plant and easily distinguishable by the color of their seedlings from the latter normal plant.

Concerning the characters waxy vs. nonwaxy, several modes of heredity are already confirmed. For example, in Triticum an inhibitor must be assumed. In corn, the certation takes place between waxy and nonwaxy pollen grains after pollination. In Avena, Pirus, Prunus, Rubus, Secale and Bryonia simple mendelian inheritance was recognized, waxy being dominant over nonwaxy except in the last species. In Canna, Pisum, Ricinus and Salix the genetic type for these characters is not simple.

The writer, moreover, found in 1946 a plant of $A$. fistulosum, which segregates nonviable pale yellow seedlings among otherwise green sisters. On the production of chlorophyll in $A$. Cepa, genetical studies have been reported since Rasmusson (1920). The complete formation of chlorophyll in it has been inferred to depend upon a set of several genes. In corn, more than twenty different dominant genes must be present if chlorophyll is to be formed, the effect of the absence of anyone of these genes being a chlorophyll deficiency. The genetical features concerning chlorophyll formation in $A$. fistulosum will be now elucidated in detail.

\section{Cross-experiments}

1. Nonwaxy. seedling

It is easy to tell nonwaxy from the normal waxy within a month after germination. The $\mathrm{F}_{1}$ plant between nonwaxy and waxy is waxy, and in the $\mathrm{F}_{2}$ offspring, segregation as indicated in the table below was observed.

Table 1. $\mathrm{F}_{2}$ of cross, nonwaxy $\times$ waxy

\begin{tabular}{l|ccc|c}
\hline \multicolumn{1}{|c|}{ Phenotyce } & waxy $(+)$ & nonwaxy $(n w)$ & Total \\
\hline $\begin{array}{l}\text { observed } \\
\begin{array}{l}\text { Expected in } \\
\text { a } 3: 1 \text { ratio }\end{array}\end{array}$ & 77 & 25 & 102 & $\chi^{2}=0.013$ \\
\hline
\end{tabular}


The result is in close agreement with a 3:1 ratio, and implies that the waxless seedling is inherited as a simple mendelian recessive.

2. Yellow seedling

A plant which was hybrid for nonviable pale yellow seedling, which was produced spontaneously, when self-pollinated, gave the following segregation in the offspring. The segregation ratio was verified immediately after germination.

Table 2. Self-fertilization of a plant spontaneously heterozygous for nonviable yellow

\begin{tabular}{l|ccc|c}
\hline \multicolumn{1}{c|}{ Phenotype } & green $(+)$ & yellow $(y)$ & Total & \\
\cline { 1 - 2 } Observed & 288 & 100 & 388 & $\chi^{2}=0.04$ \\
$\begin{array}{l}\text { Expected in } \\
\text { a } 3: 1 \text { ratio }\end{array}$ & 291 & 97 & 388 & $\mathrm{P}>0.8$ \\
\hline
\end{tabular}

It is evident that the difference between green and pale yellow is due to a single gene.

To ascertain whether the genes affecting nonwaxy and pale yellow situate on the same chromosome or on the different ones, a plant which was dihybrid for these characters was raised from a crossing of plants which were monohybrid for waxless and pale yellow.

3. Relation between nonwaxy and pale yellow seedling

A plant which was dihybrid for these characters was normal and self-pollination in it revealed a simultaneous digenic segregation, the numerical data being given in the table below.

Table 3. $F_{2}$ in a cross involving both pairs of alleles

\begin{tabular}{l|cccc|c}
\hline Phenotype & rormal $(++)$ & nonwaxy $(n w+)$ & yellow $(+y, n w y)$ & Total & \\
\hline Observed & 365 & 114 & 160 & 639 & $\chi^{2}=0.36$ \\
$\begin{array}{c}\text { Expected in a } \\
9: 3: 4 \text { ratio }\end{array}$ & 359.4 & 119.8 & 159.8 & 639 & P>0.80 \\
\hline
\end{tabular}

It was verified that these genes for absence of bloom and pale yellow act as simple recessives independently to normal waxy and green.

\section{Résumé}

In the present paper the writer has determined by an analysis of $A$. fistulosum that two genes are responsible for nonwaxy (nw) and nonviable pale yellow $(y)$ seedlings, which are inherited as recessives to normal. These genes, $n w$ and $y$, are situated on different chromosomes.

\section{Literature}

Matsuura, H. 1933. A bib'iographical monograph on plant genetics (genic analysis), 1900-1929. Sapporo. Rieman, G.H. 1931. Genetic factors for pigmentation in the onion and their relation to disease resistance
Jour. Agri. Res. 42: 251-278.

Yamaura, A. 1949. Genetical studies of A. fistulosum I. (in Japanese) Kagaku 19 (12): 568. 